Article

\title{
Securing Retirement at a Young Age. Exploring the Intention to Buy Longevity Annuities through an Extended Version of the Theory of Planned Behavior
}

\author{
Costanza Nosi ${ }^{1, *}$, Antonella D’Agostino ${ }^{2}$, Margherita Pagliuca ${ }^{2}$ and Carlo Alberto Pratesi ${ }^{3}$ \\ 1 Department of Human Studies-Communication, Education, and Psychology, LUMSA University of Rome, \\ Rome 00193, Italy \\ 2 Department of Management and Quantitative Studies, Parthenope University of Naples, Naples 80132, Italy; \\ dagostino@uniparthenope.it (A.D.); margherita.pagliuca@uniparthenope.it (M.P.) \\ 3 Department of Management Studies, Roma Tre University, Rome 00145, Italy; carloalberto.pratesi@uniroma3.it \\ * Correspondence: c.nosi@lumsa.it
}

Received: 11 April 2017; Accepted: 16 June 2017; Published: 20 June 2017

\begin{abstract}
Since the early 90s, Italy has undergone radical changes in the regulations of the public pension system aimed at mending its main drawbacks and improving sustainability in the long run. The reforms were intended to recover the national economy through a significant reduction of benefits by increasing, particularly for younger people, individual responsibility for the accumulation of retirement wealth. Adopting an enhanced version of the Theory of Planned Behavior (TPB), which includes affective reactions, the present paper aims to understand the factors influencing the intention to enroll in a private pension plan through the purchase of longevity annuity coverage on the part of young adults. A purposive sample of 7480 Italian people aged 25-35 participated in the survey. Collected data were analyzed adopting an ordinal logistic regression (OLR) model. The findings confirm the predictive power of the TPB in the financial field of longevity annuity buying, show that anticipated affective reactions increase the predictive power of the TPB model, and reveal that the influence of the investigated constructs varies alongside people's willingness to purchase. The outcomes provide useful recommendations to the policy maker and private companies to favor the adoption of wide-spread desired behaviors among citizenships.
\end{abstract}

Keywords: public pension system; private pension plan; longevity annuities; young adults; theory of planned behavior (TPB); anticipated affective reactions

\section{Introduction}

Since the early 90s, Italy has undergone radical changes in the regulations of the public pension system aimed at mending its main drawbacks and improving sustainability in the long run. The reforms were intended to recover the national economy through a significant reduction of benefits by increasing, particularly for younger people, individual responsibility for the accumulation of retirement wealth [1].

According to Fornero and Monticone [1], the extent to which people secure themselves against longevity risk - that is, the risk of outliving their savings in modern societies-is important for multiple reasons. Firstly, the increasing average life span raises the issue of ensuring adequate resources throughout people's advanced life. Indeed, it has been recognized that the sufficiency of later life financial assets has a direct impact on elderly poverty rates [2]. Second, if people neglect to set aside sufficient resources to guarantee themselves a comfortable retirement, social support systems will be hampered by an increasing financial burden due to the greater dependence the elderly will exert both on public and private assistance institutions [3]. Finally, the way individuals choose to 
protect themselves against longevity risk at present can have a substantial impact on the amount of intergenerational transfers within a given society, influencing the wealth distribution of forthcoming generations. Despite this, the annuitization rate in most advanced societies is still small and has only seen a slow rise over the last few years [4].

With specific reference to annuity-buying behavior, research efforts have mainly been concentrated on the elderly's purchase decision-making (i.e., on immediate annuities). Fewer studies are aimed at shedding light on the intention to buy longevity annuities, specifically among young adults. Nevertheless, the young are the most adversely affected by the pension system reforms that have recently taken place in all advanced economies, which progressively reduce the amount of public financial resources to be allocated to retirees. In fact, younger people will face a higher risk that their savings will not be enough to ensure a comfortable retirement [5].

Therefore, the present research aims to explore the determinants of longevity annuity-buying behavior of Italian young adults. Intention to purchase longevity annuities is investigated adopting an enhanced version of the theory of planned behavior (TPB) [6], which adds anticipated affective reactions [7] to the traditional variables of the model. The findings confirm the predictive power of the TPB in the financial field of longevity annuity buying, show that anticipated affective reactions increase the predictive power of the TPB model, and reveal that the influence of the investigated constructs varies alongside people's willingness to purchase. The outcomes provide recommendations to tailor appropriate and effective initiatives to prompt people's purchase intention of longevity annuities, supporting the policy maker and private companies in favoring the adoption of wide-spread desired conducts among citizenships.

\section{The Italian Pension System and Longevity Annuities}

Starting from 1992, seven subsequent reforms (Legislative Decree 503/1992, Law 335/1995, Law 449/1998, Enabling Act 243/2004, Legislative Decree 252/2005, and Legislative Decree 201/2011) have radically transformed the Italian pension system, turning the dominant single-pillar defined benefit scheme into a multi-pillar defined contribution model, while gradually raising the requirements for access to retirement (age and years of contribution) and harmonizing the rules between professions and genders [8]. Such measures are analogous to those that have been implemented in recent years by multiple EU member states (including Austria, Belgium, Bulgaria, Denmark, Hungary, Luxembourg, Romania, and Slovenia) aimed at reforming their statutory public pension schemes [9].

At present, the national pension system consists of three pillars.

The first pillar is a public, compulsory, unfunded pay-as-you-go system (A pay-as-you-go (PAYG) pension system is a "system in which retirement benefits are financed by contributions levied from current workers, as opposed to a funded system in which contributions are invested to pay for future benefits" (see Oxford Dictionary, sub vocem "pay-as-you-go pension system")), which comprises entitlements derived from mandatory contributions to retirement saving scheme. The other two pillars provide additional coverage outside the public program and can be joined on a voluntary basis. The second pillar, entailing occupational and earnings-related plans, is a collective funded system. It includes pension funds, which can be managed by different entities, such as insurance companies, banks, brokerage or asset management companies. The second pillar can be divided into two broad subsets:

- Closed (contractual) pension funds, which are carried out either as company pension funds by a single - and in most cases large - enterprise or as industry-wide pension funds established by employers' associations and trade unions for a specific group of participants, or as regional/territorial pension funds;

- Open pension funds, which operate for generic groups of participants and set no entry requirements with respect to individual enrollment, enabling membership also to non-working people, such as housewives and students. 
The third pillar covers personal savings plans consisting of voluntary contributions by individuals. These individual plans, labeled PIPs (Piani Individuali Pensionistici) in Italy and introduced to the market in 2001, are contracted on a private basis between the subscriber and an insurance company [10]. As longevity annuities, PIPs are contracts that are acquired today that defer payments until some future point in time, i.e., when the annuitant is pensioned off. Starting from that point, the contract guarantees an income to the subscriber through the provision of regular payments throughout the person's advanced life. The majority of longevity annuities on the Italian market also provide a designated beneficiary with a lump-sum payment in the case of premature death of the annuitant. Accordingly, in addition to guaranteeing an income throughout the policyholder's late life, this product constitutes a suitable method to fulfill bequest motives. Then, similarly to buying any other type of (financial or insurance) supplemental retirement product, purchasing a longevity annuity may represent a suitable method to ensure people a comfortable advanced life. At the same time, this would reduce the financial pressure on social support systems due to the lower reliance that the elderly would exert on public assistance structures.

At the end of 2012-the year the present research was realized-longevity annuity subscribers in Italy were $1,777,024$, accounting for little less than $3 \%$ of the entire resident population. Specifically, 367,844 of them were aged $25-34$ (56.8\% males), representing $5.2 \%$ of residents aged $25-34$ in the country at the time [11,12]. Despite increase in subscriptions $(405,467$ and 432,939 in years 2013 and 2014 respectively) $[13,14]$, the amount of longevity annuity purchases by young individuals is claimed to be still negligible [10].

Until now, the public measures aimed at increasing the enrollment in integrative pension systems have been mainly focused on financial incentives (mostly in the form of tax deductions) that could be gained by subscribers and achieved through widespread informational campaigns [15]. These interventions have largely disregarded the socio-demographic characteristics of the possible annuitants and the real motives underlying their choices. Furthermore, in targeting younger prospects, insurance and financial companies have mainly adopted the strategies that are typically used for unsought products [16]. These are products that customers do not think of buying or are unaware of and are often characterized by no immediate tangible benefits realized at purchase, therefore spurring individuals to defer the buy. Accordingly, private companies commonly employ aggressive marketing campaigns that exploit different tools, including well-trained and pushy sales professionals, sales promotion, and direct marketing combining both informational and persuasive communication strategies $[17,18]$. Very often, these strategies disregard the possible influence that attitudes, and mostly emotions, could exert on individuals' decision-making.

\section{Predicting Behavioral Decisions}

A large body of interdisciplinary literature has investigated consumers' intentions to engage in behaviors. The theory of reasoned action (TRA) [19], as well as its extended version, the theory of planned behavior [6], has served as the basis for much of the work in this research field. However, because these models are cognitive-based, a frequently cited drawback is that they provide only a partial—cognitively driven—assessment of conduct and do not directly account for affect in predicting behavior e.g., Fishbein and Ajzen [19]. Quite numerous studies instead claim that considering emotions would help expand knowledge about individuals' disposition to engage in a behavior e.g., Fitzmaurice [20] also in the financial field [21]. In this research area, the attention of scholars has been largely devoted to forward-looking emotions. These are, in most cases, negative emotions that people experience when they anticipate that a future circumstance could be different (and essentially better) if they choose or behave differently in the present [22]. These emotions include various negative feelings, such as regret, worry, and guilt, which a person can experience when thinking about the outcomes of engaging (or of not engaging) in a specific behavior [23]. Current decisions are therefore said to be influenced by negative affective statuses that individuals could experience once having made—or not made—a choice and that they try to avoid [7]. Until now, however, studies aimed 
at testing extended versions of the reasoned action or planned behavior approaches by including anticipated regret belong mainly to the health- and security-related research domains, e.g., health protection [24], smoking initiation [25], self-harm [26].

Whereas saving behavior has been extensively studied in the literature within multiple disciplinary fields, such as economics, finance, psychology, marketing and consumer behavior, to the best of the authors' knowledge, no previous study has aimed to investigate longevity annuity-buying intention adopting the theory of planned behavior and testing whether the inclusion of an affective construct could allow the predictive power of the model to be increased. Furthermore, whereas socio-demographic factors have been recognized as relevant in influencing intention to behave [6], no prior research has been made to verify whether the consideration of some social and demographic characteristics of individuals may improve the capability of the TPB to predict behavior in the field of longevity annuity buying.

\section{The Theory of Planned Behavior and Anticipated Affective Reactions}

\subsection{The Theory of Planned Behavior}

The theory of planned behavior [6] is an extension of the theory of reasoned action [19] required, according to the author, by the foremost model's inadequacies in dealing with behaviors over which people have only partial volitional control. Analogously to the TRA, the core concept of the TPB is intention, described as an individual's motivation in his or her mindful decision to make an effort in performing a behavior [27]. According to the model, the greatest part of human behaviors can be predicted based on intention given that such behaviors are under volitional control and people can decide at will to perform or not to perform them [28]. In the TPB perspective, behavioral intention is influenced by three components [6]: attitude toward the behavior, the extent to which a person has a positive or negative appraisal of the behavior in question; subjective norm, the perceived social pressure to achieve or not to achieve the behavior; and perceived behavioral control, that is, a person's perception of how difficult or easy is to perform the behavior [29].

Attitudes are individual components resulting from the person's valuation of the benefits and costs of engaging in the behavior. Individuals are said to ponder the consequences of alternative actions before taking them, and they are more likely to engage in activities they associate with desirable results [30]. Subjective norms represent a social component that arises from the perceptions of salient referents' opinions about what a person should (or should not) do. Salient referents are important others, such as family members, partners, peers, and friends, who are able to affect an individual's choices [31]. The theory postulates that people's behavioral intention is more likely to be affected by significant referents' views when people are more willing to undergo influence from these specific referents. Finally, perceived behavioral control expresses the perceived complexity of engaging in a behavior, mirroring both anticipated barriers and past experience. Generally, the easier the perceived performance of the behavior, the greater the behavioral intention [32].

Given its strong predictive power, the TRA has been used to forecast behavioral intentions and behaviors in several fields of investigation, both in its original and in its augmented versions, such as the TPB or models including additional constructs in their conceptual framework: renewable energy use [30], intention to purchase genetically modified food [33], smart cards adoption [34], job choice intention [35], ecolabel product usage [36].

\subsection{The Sufficiency of the Theory}

Although quite numerous meta-analyses e.g., [37] validate the predictive effectiveness of the TPB, demonstrating the large effect size of the model, a considerable percentage of the variance in either behavioral intentions or actual behavior remains unexplained [38]. In his article on the TPB [6], the author himself questions the sufficiency of the model, claiming that there might be further variables able to influence individuals' behavioral intention as well as their behavior. Specifically, he recognizes 
that intention to behave might also be the result of affective beliefs, in addition to those formed by a merely cognitive processing. Furthermore, subjective norm, as a normative pressure, may not be the only force spurring individuals. Particularly in definite contexts, people could be affected not only by social pressure but also by their personal thoughts of moral duty, that is, their sense of obligation to engage or not to engage in specific actions [39]. In time, in order to increase the predictive power of the $\mathrm{TPB}$, a multiplicity of additions have been proposed by the literature, including different constructs besides the three fundamental variables of the model. These additional constructs include, among others, moral norms [40]; perceptions of control and self-efficacy [41]; conscientiousness [24]; moral intensity in ethical decision-making [42], anticipated emotions [43]; past behavior [44].

\subsection{Anticipated Affective Reactions}

Cognition-based multi-attribute models, such as the TPB, postulate that individuals' overall attitude toward a behavior comprises a behavior-evaluative assessment based on belief strength and its evaluative feature. In other words, based on the utility paradigm, these theories assume that consumers are rational beings, able to correctly assess and ponder the outcomes of their actions, and who behave reasonably with the aim of maximizing their self-interest [45]. Thus, behavioral decisions are assumed to be made disregarding the affective component of attitude [46].

Nevertheless, over the last two decades, multiple studies have examined the impact of anticipations of affect connected with engaging in a behavior augmenting the predictive power of theories that include only cognitive variables [7]. Among them, attention has been devoted to the undesirable feelings people could experience thinking about their future actions.

Anticipated negative reactions or emotions are negative affective statuses that can be experienced pre-behaviorally by individuals and can therefore have some bearing on their subsequent conduct [47]. According to Abraham and Sheeran [7], anticipated affective reactions (AARs) can be conceptually distinguished from affective attitudes of a broader type. While these latter are expected to arise during the performance of a behavior, AARs are emotions that are expected to follow after the engagement or non-engagement in a behavior. Furthermore, affective attitudes tend to concentrate on hedonic feelings, such as amusement and joy, whereas AARs tend to focus on awkward emotions, such as regret, guilt, and worry. Finally, the literature on AARs has generally leaned toward investigating the undesirable consequences of not performing a behavior rather than the desirable effects of performing a behavior. In other words, the majority of the literature has tended to explore situations in which individuals feel anticipated negative emotions for not engaging in a behavior they wish they had engaged, demonstrating the utility of distinguishing between anticipated action emotions and anticipated inaction emotions.

Despite the recognition that pre-behavioral feelings do exert some influence on intention and overt behavior [48], further research is needed to ascertain whether and how effectively anticipated affect contributes to the prediction of intentions after TPB constructs have been taken into account. Previous attempts to give such evidence have in fact provided contradictory findings. Sandberg and Conner [49] performed a meta-analysis to statistically ascertain the additional effects of anticipated negative emotion on the prediction of intention and behavior after the TPB variables. The authors found, over a number of studies, a strong relationship between anticipated emotion and intention and that anticipated emotion significantly and independently added to the prediction of intentions over and above the constructs of the TPB model. Weak or non-significant relationships instead were found by Richetin et al. [48]. Furthermore, as Rivis et al. [50] note, even within the same behavioral field, results regarding the predictive value of anticipated emotion have been conflicting.

\section{Materials and Method}

\subsection{The Sample}

Data for this investigation were collected by means of a survey conducted in 2012 . Skilled investigators were enrolled to submit the questionnaire face-to-face to people aged between 
25 and 35 who had no retirement coverage other than the public pension belonging to their personal network of relationships. The sampling method was therefore of a purposive type. In all, 8352 questionnaires were returned. After the data cleaning, 7480 questionnaires were considered valid for elaboration and were analyzed. Table 2 summarizes the main characteristics of the sample.

\subsection{The Measures}

Behavioral intention was defined as the purchase (action) of a longevity annuity policy for ones-self (context) within the next two years (time frame). The questionnaire was designed to investigate the interviewee's intention to buy a longevity annuity, overall attitude, subjective norms, perceived behavioral control, anticipated inaction regret, and some socio-demographic characteristics.

Attitude (ATT). Overall attitude toward the behavior of purchasing a longevity annuity was operationalized using a four-item, seven-point semantic differential scale: 1 (harmful) to 7 (beneficial); 1 (foolish) to 7 (wise); 1 (unnecessary) to 7 (essential); 1 (difficult) to 7 (easy) $(\alpha=0.80$ ).

Subjective Norm (SN). The subjective norm was assessed by obtaining the respondents' level of agreement to two statements related to their perception about what salient referents (people they care for and those who influence their decisions) think they should do relative to the behavior in question, namely, whether to buy the longevity annuity. A seven-point Likert scale, where $1=$ strongly disagree and $7=$ strongly agree, measured the respondents' level of agreement $(\alpha=0.89)$.

Perceived Behavioral Control (PBC). This construct was measured with three items, followed by a seven-point scale, anchored as $1=$ extremely unlikely and $7=$ extremely likely. This construct was used to assess the respondents' perception of possessing the necessary resources, namely, money, ability to comprehend the annuity's functioning, and the time and energy needed to buy a longevity annuity $(\alpha=0.53$ ) (By far the most frequently reported reliability index between scores derived from a scale is Cronbach's alpha. Multiple empirical studies assert that the value of coefficient alpha must be at least 0.70 . However, as noted by Ref. [51], this frequently mentioned criterion, claimed to have been formulated by Ref. [52], is essentially misleading. In his review of the marketing and consumer behavior literatures, Ref. [53] highlights that the alpha coefficient varies based on selected individual difference constructs and research design characteristics. Finally, the value of Cronbach's alpha not only depends on the correlation between the items in the tested scale but also on the number of items. Thus, a value of 0.53 for a three-item scale is considered acceptable).

Anticipated Inaction Regret (AIR). Anticipated emotion was measured on a two-item seven-point scale, anchored as $1=$ strongly disagree and $7=$ strongly agree. AIR was used to assess the participant's likelihood of feeling guilt and regret if they had not purchased a longevity annuity $(\alpha=0.85)$.

The Cronbach's alpha coefficients range from 0.53 to 0.89 , indicating an acceptable level of reliability.

Behavioral intention (BI). In the present study, intention was considered on a single-item seven-point Likert scale (It is worth noting that in a previous article published by the same authors [54], which presented a different study based on the same dataset, BI was considered as a construct measured on a three-item seven-point Likert scale), where $1=$ extremely unlikely and $7=$ extremely likely that one will perform the purchasing behavior. The items and theoretical constructs are shown in Table 1.

Finally, gender was operationalized as a dummy variable where $0=$ female and $1=$ male. Education and household income were operationalized as dummies as well, where $1=$ "low educational level" (possession of a primary school diploma or a lower qualification) and 0 otherwise, and $1=$ "low household income" (lower than 15,000 Euros) and 0 otherwise.

The outcomes of the pilot test with 50 people revealed that the questionnaire had an acceptable level of reliability. Only minor rewording was done to improve question clarity.

It is worth noting that although different socio-demographic characteristics may have potential relevance for influencing the intention to buy a longevity annuity, there is nothing in the theory of planned behavior to suggest which of these characteristics deserve our attention. Therefore, potentially relevant background factors have been identified based on the available information and 
their significant effect has been tested in the econometric model. The descriptive statistics presented in Table 2 show that the gender distribution is equally shared between women and men and that about $53 \%$ of interviewed individuals have an income lower than 15,000 euros. This latter finding was expected given the mean age of the sample. Respondents are instead under-represented in the low educational level with respect to the Italian population in the same age range because of the non-probability sampling used.

Table 1. Items and theoretical constructs.

\begin{tabular}{|c|c|}
\hline Items & Constructs \\
\hline $\begin{array}{l}\text { Purchasing a longevity annuity in the next two years is harmful/beneficial. (G1) } \\
\text { Purchasing a longevity annuity in the next two years is foolish/wise. (G2) } \\
\text { Purchasing a longevity annuity in the next two years is unnecessary/essential. (G3) } \\
\text { Purchasing a longevity annuity in the next two years is difficult/easy. (G4) }\end{array}$ & Attitude (ATT) \\
\hline $\begin{array}{l}\text { Most of the people I care about think I should purchase a longevity annuity. (H1) } \\
\text { Most of the people who influence my decisions think I should purchase a longevity annuity. (H2) }\end{array}$ & Subjective Norm (SN) \\
\hline $\begin{array}{l}\text { I have the necessary money to purchase a longevity annuity. (F1) } \\
\text { I am able to understand how a longevity annuity functions. (F2) } \\
\text { I have time and energy to dedicate to the purchase of a longevity annuity. (F3) }\end{array}$ & $\begin{array}{l}\text { Perceived Behavioral } \\
\text { Control (PBC) }\end{array}$ \\
\hline $\begin{array}{l}\text { If I did not buy a longevity annuity in the next two years, I would feel guilt. (M1) } \\
\text { If I did not buy a longevity annuity in the next two years, I would feel regret. (M2) }\end{array}$ & $\begin{array}{l}\text { Anticipated Inaction } \\
\text { Regret (AIR) }\end{array}$ \\
\hline I intend to buy a longevity annuity in the next two years. (I1) & Behavioral Intention (BI) \\
\hline
\end{tabular}

Table 2. Main characteristics of the sample.

\begin{tabular}{|c|c|c|c|c|}
\hline & & Average Value BI & $\%$ of 7 in $\mathrm{BI}$ & Row \% \\
\hline \multicolumn{2}{|c|}{ Male } & 3.38 & $4 \%$ & $53 \%$ \\
\hline \multicolumn{2}{|c|}{ Female } & 3.61 & $6 \%$ & \\
\hline \multicolumn{2}{|c|}{ Low education } & 3.62 & $9 \%$ & $6 \%$ \\
\hline \multicolumn{2}{|c|}{ Medium/high education } & 3.48 & $5 \%$ & \\
\hline \multicolumn{2}{|c|}{ Low income } & 3.32 & $4 \%$ & $53 \%$ \\
\hline \multicolumn{2}{|c|}{ Medium/high income } & 3.68 & $6 \%$ & \\
\hline \multirow{5}{*}{ Age } & $25-26$ & 3.35 & $5 \%$ & $39 \%$ \\
\hline & $27-28$ & 3.51 & $5 \%$ & $21 \%$ \\
\hline & $29-30$ & 3.63 & $6 \%$ & $15 \%$ \\
\hline & $31-32$ & 3.67 & $6 \%$ & $10 \%$ \\
\hline & $33-35$ & 3.55 & $6 \%$ & $14 \%$ \\
\hline \multicolumn{2}{|c|}{ Total sample } & 3.49 & $5 \%$ & $100 \%$ \\
\hline
\end{tabular}

Furthermore, the observed percentage of respondents who indicated a 7 for BI is about $5 \%$. Assuming that a 7 indicates that they will purchase a longevity annuity, this sample proportion is very similar to the share of longevity annuity subscribers (aged 25-34) in Italy presented in Section 2 $(5.2 \%)$. Such a result provides evidence that the intention to purchase a longevity annuity found in the present study is fairly in line with the actual behavior at the national level (Whereas in Table 2 the reported data refers to the entire sample (individuals aged 25-35), taking into consideration that the official statistics consider the 25-34 age range, the proportion of those who indicated a 7 for BI has been also calculated excluding 35 years old respondents. The percentage remains unvaried and accounts for around 5\%). Finally, the average values of BI and percentages of 7 vary by socio-demographic characteristics even if differences are not very large, especially for age. 


\section{Statistical Methodology}

\subsection{Confirmatory and Exploratory Factor Analysis}

Both confirmatory factor analysis (CFA) and exploratory factor analysis (EFA) are commonly used to reduce the dimensionality of data $[55,56]$. Factor analysis operates on the notion that measurable and observable items can be reduced to fewer latent (unobservable) variables (factor scores). To predict and test the hypothesized factor structure, we first used CFA. CFA is part of the larger family of methods known as structural equation modeling (SEM), and it provides a powerful statistical tool for testing a variety of hypotheses about a set of measured items. In CFA, the predicted factor structure of the observed items is translated into the complete covariance matrix over these items. Then, this matrix is adjusted to the actual covariance matrix and subsequently compared with it. The discrepancy between the two matrices is expressed by a number of "goodness of fit" indices [57]. Namely, the root mean squared error of approximation (RMSEA), the comparative fit index (CFI), the standardized root mean squared residual (SRMR), the Tucker-Lewis index, the non-normed fit index (TLI) and the CD index, which gives information similar to the R-squared value provided by OLS and other forms of regression. These five indices are often reported in CFA studies [58]. Although the most common estimation method within CFA is maximum likelihood (ML), we used an asymptotically distribution-free (ADF) estimator [59], which, by taking into account the kurtosis of the observed variables, avoids the assumption of multivariate normality (The normality assumption is usually not met when the observed data are discrete (as occurs when using ordinal scales). The ADF estimator requires very large samples to behave like a $\chi^{2}$ [60], and models with more than 20 variables are not feasibly estimated [61]). We adopted this estimation method while aware that it could have had an effect on the incremental fit indexes (CFI and TLI), lowering their value [62]. To validating the CFA results, we also performed EFA using a polychoric correlation matrix (When EFA is used to test the construct validity of a measurement instrument, it is important to take into account the measurement scale that is being used [63]) and fixed exactly four factors. The results of the CFA and EFA are summarized in Table 2.

\subsection{Ordinal Logit Regression Analysis}

The information about the factors is used in subsequent analyses. We computed the factor scores to represent each individual's placement on the factor(s) identified from the CFA [64]. To investigate our research questions, we used these factor scores as covariates in nested ordinal logit regression models by sequentially adding one or more blocks of variables. Finally, we reported comparison tests between the nested models. The results are presented in Table 3. The ordinal logit regression accounts for the ordinal measurement scale of the dependent variable and, therefore, was used to model the relationship between BI and the investigated constructs (ATT, SN, PBC, and AIR).

In ordinal logistic regression, the event of interest is observing a particular score or less. In our case, the dependent variable is behavioral intention, measured on a single-item seven-point Likert scale, where 1 = extremely unlikely and 7 = extremely likely. The independent variables considered in the models are the factor scores and the investigated socio-demographic variables (gender, education, and household income). Each factor score represents the score of each person on the underlying latent variable, and it is a continuous variable, where high scores mean the person gave greater than average ratings with respect to the specific latent trait. The socio-demographic factors are considered moderating variables in the model. In the elaboration, the odds (The last category does not have an odds associated with it, as the probability of scoring up to and including the last score is 1) were modeled as follows:

$$
\theta_{j}=\frac{P(B I \leq j)}{P(B I>j)}, j=1, \ldots, 6
$$

The ordinal logistic model $[65,66]$ for BI is specified as: 


$$
\log \theta_{j}=\alpha_{j}-\beta X, j=1, \ldots, 6
$$

where $j$ goes from 1 to the number of categories minus $1, \alpha_{j}$ and $\beta$ are unknown parameters to be estimated, and $X$ is the vector of predictors. The $\alpha_{j}$ parameters (labeled cut-points) are interpreted as the adjusted log odds of being in category $j$ or lower on the response variable given the set of predictors. Under this specification, the curves on the various cumulative logits are parallel, that is, the distance between each category is equivalent (proportional odds model assumption). Because the relationship between all pairs of groups is the same, there is only one set of coefficients $\beta$ across all cut-points.

The steps we have followed in order to test our research questions are based on the covariates included in the $\mathrm{X}$ vector. Thus, we compared different models as follows:

Model 1: $X=\mathrm{f}(\mathrm{ATT}, \mathrm{SN}, \mathrm{PBC})$

Model 2: $X=\mathrm{f}(\mathrm{ATT}, \mathrm{SN}, \mathrm{PBC}, \mathrm{AIR})$

Model 3: $X=f(A T T, S N, P B C$, AIR, socio-demographic factors)

The proportional odds assumption can be assessed by the Brant test [67]. The null hypothesis is that there is no difference in the coefficients between models. If the null hypothesis is rejected, a generalized ordered logit model can be estimated [68,69].

Accordingly, Equation (2) becomes:

$$
\log \theta_{j}=\alpha_{j}-\beta_{j} X, j=1, \ldots, 6
$$

If only certain predictors violate the assumption, then their effects can be estimated freely across different categories of the dependent variable.

\section{Results}

The CFA, EFA, and reliability analysis results are summarized in Table 3. The SRMR value is 0.056. The SRMR takes values between 0 and 1. The lower the SRMR, the better the model fit [70,71]. Index values less than 0.08 are generally considered acceptable. The RMSEA value is 0.06 . A value of 0 indicates perfect fit. Reference [72] suggested $\leq 0.06$ as a cut-off value for a good fit. The CD value of 0.998 indicates a good fit. The CFI value is 0.881 , and the TLI value is 0.828 . Both indices range from 0 to 1 . Higher values indicate better model fit, and Reference [72] proposed $\geq 0.95$ as a cut-off value for a good fit. Thus, the last two indices do not meet the cut-off criteria. Nevertheless, as we acknowledged above, the ADF method generally tends to reduce the value of incremental fit indexes [60]. Looking at the goodness of fit statistics, the fit of the model to the data may be considered acceptable.

When performing EFA using extraction with orthogonal Varimax rotation to validate the CFA results, the outcomes show that the items form four latent factors. The pattern matrix offers a clearer picture of the relevance of each item in the latent factor, with high factor loadings (ranging from 0.411 to $0.787,0.779$ to $0.782,0.79$ to 0.802 , and 0.344 to 0.509 on the four latent factors) and minimal cross-factor loadings. Therefore, ATT is mostly defined by G1, G2, G3, and G4; SN by H1 and H2; AIR by $\mathrm{I} 1$ and I2; and PCB by F1, F2 and F3.

The results of the likelihood ratio (LR) test are presented in Table 4 (Preliminary analyses also tested the effect of age introducing into Model 3 a set of dummy variables in order to model age not parametrically. The LR test clearly showed a very not statistically significant age effect $\left(\chi_{10}^{2}=15.69\right.$, Prob $>\chi_{10}^{2}=0.1089$ ). For this reason, we did not include age in Table 5. Results are available upon request from the authors.). The LR chi-square of 5601.67 with a $p$-value of 0.0000 demonstrates that our model as a whole is statistically significant compared to the null model with no predictors. The two further significant LR statistics indicate a significant improvement over the previous estimated model. This means that the current model gives a significantly better prediction than the model just estimated at the previous step. Thus, the influence of AIR on behavioral intention once the fundamental TPB constructs have been accounted for is confirmed (LR chi-square is 428.91, with a $p$-value of 0.0000 ). 
The moderating effect of at least one demographic variable is also confirmed (LR chi-square is 19.43, with a $p$-value of 0.0001 ) even if the relative improvement of the predictive capability of the model decreases with respect to the effect played by AIR. Furthermore, the Variance Inflation Factors (VIFs) (In order to calculate the VIF (1/(1 - R-square)), we regressed each of the independent variables on the others and calculated the R-square and pseudo-R-squared values for continuous and dummy variables respectively.) for each predictor were calculated to test for multicollinearity. Ranging from 1.01 to 3.15, all VIFs are below the recommended cut-off threshold of 10 [73]; hence, multicollinearity is not an issue in this study.

Table 5 (In general, because interpretation of the ordered logit model is not dependent on the cut-points, we focus only on the effects of substantive predictors) shows that the estimated odds ratios of ATT, SN, and PBC are statistically significant at the $1 \%$ level in each model as well as the coefficient of AIR (We present the results in terms of proportional odds ratios. They can be obtained by exponentiating the ordered logit coefficients. Because the ordered logit model estimates a single equation (regression coefficients) over the levels $\mathrm{j}$ of the dependent variable (see Equation (1)), the interpretation of odds ratios is that for a one-unit change in the predictor variable, the odds for cases in a group that is greater than $j$ versus less than or equal to $j$ are the proportional odds times larger). Since odds ratios are useful indicators of the strength of the relationship, findings confirm that attitudes are the primary determinants of behavioral intention, followed by SN and PBC, similarly to other empirical studies based on the theory of planned behavior [74,75]. Findings also suggest that when the AIR component is added to the model its effect is even stronger than the effect of perceived behavioral control. The remaining predictor variables (Gender, Education, and Household income) are not statistically significant except for Gender. Therefore, only gender has a significant moderating effect on behavioral intention. The odds ratios (greater than one) for ATT, SN, PBC, and AIR mean that the likelihood of being in a higher BI level increases with high scores for attitude, subjective norms, perceived behavioral control, and anticipated inaction regret, respectively. In particular, we would say that for a one unit increase in ATT (SN, PBC, AIR, respectively), the odds of being beyond a particular BI level are $2.71(1.47,1.18,1.50$, respectively) times greater, given that the other variables in the model are held constant.

Table 3. CFA, EFA and reliability analysis.

\begin{tabular}{|c|c|c|c|c|c|}
\hline \multirow{6}{*}{ CFA } & \multicolumn{5}{|c|}{ Fit Statistic Indexes } \\
\hline & RMSEA & 0.063 & & & \\
\hline & CFI & 0.881 & & & \\
\hline & TLI & 0.828 & & & \\
\hline & SRMR & 0.056 & & & \\
\hline & $\mathrm{CD}$ & 0.998 & & & \\
\hline \multirow{13}{*}{ EFA } & \multicolumn{5}{|c|}{ Correlations between Items and Latent Variables (Factor Loading) } \\
\hline & ITEM & ATT & SN & PBC & AIR \\
\hline & G1 & 0.756 & 0.238 & 0.146 & 0.125 \\
\hline & G2 & 0.787 & 0.250 & 0.104 & 0.103 \\
\hline & G3 & 0.663 & 0.273 & 0.119 & 0.243 \\
\hline & G4 & 0.411 & 0.153 & 0.370 & 0.203 \\
\hline & $\mathrm{H} 1$ & 0.277 & 0.779 & 0.086 & 0.280 \\
\hline & $\mathrm{H} 2$ & 0.251 & 0.782 & 0.095 & 0.285 \\
\hline & F1 & 0.234 & 0.183 & 0.499 & 0.175 \\
\hline & F2 & 0.182 & 0.013 & 0.344 & -0.186 \\
\hline & F3 & 0.294 & 0.235 & 0.509 & 0.108 \\
\hline & I2 & 0.187 & 0.271 & 0.054 & 0.790 \\
\hline & I3 & 0.096 & 0.251 & 0.056 & 0.802 \\
\hline
\end{tabular}


Table 4. LR tests.

\begin{tabular}{ccccc}
\hline Model & LL & LR & Df & Pr $>$ LR \\
\hline 1 & -11255 & 5601.67 & 3 & 0.0000 \\
2 & -11041 & 428.91 & 1 & 0.0000 \\
3 & -11033 & 19.43 & 3 & 0.0001 \\
\hline
\end{tabular}

Table 5. Ordered logit regression—odds ratio results (s.e. in brackets).

\begin{tabular}{|c|c|c|c|}
\hline & Model 1 & Model 2 & Model 3 \\
\hline & Odds Ratio & Odds Ratio & Odds Ratio \\
\hline ATT & $\begin{array}{c}2.815^{* * *} \\
(0.102)\end{array}$ & $\begin{array}{c}2.717^{* * *} \\
(0.099)\end{array}$ & $\begin{array}{c}2.706^{* * *} \\
(0.098)\end{array}$ \\
\hline $\mathrm{SN}$ & $\begin{array}{c}1.754^{* * *} \\
(0.037)\end{array}$ & $\begin{array}{c}1.474^{* * *} \\
(0.034)\end{array}$ & $\begin{array}{c}1.471^{* * *} \\
(0.034)\end{array}$ \\
\hline PBC & $\begin{array}{c}1.194^{* * *} \\
(0.046)\end{array}$ & $\begin{array}{c}1.176^{* * *} \\
(0.045)\end{array}$ & $\begin{array}{c}1.178^{* * *} \\
(0.046)\end{array}$ \\
\hline AIR & & $\begin{array}{c}1.503^{* * *} \\
(0.030)\end{array}$ & $\begin{array}{l}1.506^{* * *} \\
(0.030)\end{array}$ \\
\hline Gender (1 = M) & & & $\begin{array}{c}0.854^{* * *} \\
(0.037)\end{array}$ \\
\hline Household income (1 = low) & & & $\begin{array}{c}0.982 \\
(0.043)\end{array}$ \\
\hline Education $(1=$ low $)$ & & & $\begin{array}{c}1.073 \\
(0.101)\end{array}$ \\
\hline$\chi^{2}(\mathrm{df})$ & $5602(3)$ & $6031(4)$ & $6045(7)$ \\
\hline Pseudo $\mathrm{R}^{2}$ & 0.199 & 0.215 & 0.215 \\
\hline $\mathrm{N}$ & 7480 & 7480 & 7480 \\
\hline
\end{tabular}

Finally, the proportional odds ratio of comparing males to females on BI, given that the other variables in the model are held constant, is approximately equal to 0.85 . Thus, the odds of the combined categories of a high versus low level of BI are 0.85 times lower for males compared to females, given the other variables are held constant in the model.

Even if these results are relatively straightforward, intuitive, and easy to interpret, we next test for the proportional odds assumption in order to gain a better understanding of the findings. Table 6 presents the results of both a global test of whether any predictor violates the parallel lines assumption as well as tests of the assumption for each predictor separately.

Table 6. Brant test of parallel regression assumption.

\begin{tabular}{cccc}
\hline & $\chi^{2}$ & $p$-Value & Ddf \\
\hline All (Full model) & 276.17 & 0.000 & 35 \\
ATT & 64.67 & 0.000 & 5 \\
SN & 19.02 & 0.002 & 5 \\
PBC & 9.10 & 0.105 & 5 \\
AIR & 93.76 & 0.000 & 5 \\
Gender & 28.52 & 0.000 & 5 \\
Household income & 6.04 & 0.303 & 5 \\
Education & 28.56 & 0.000 & 5 \\
\hline
\end{tabular}


The Brant test for the full model $\left(\chi^{2}=276.17, p=0.000\right)$ indicates that the proportional odds assumption for the full model was violated. To identify which predictor variables violated the assumption, separate Brant tests were run for each predictor variable.

The results indicate that all coefficients differ greatly across regressions except for the coefficients of "Household income" and "PBC", whose difference is not statistically significant ( $p$-values greater than 0.05).

In Table 7, we present the results of partial proportional odds models, where the parallel lines constraint is relaxed only for those variables where it is not justified. In other words, Table 7 presents a series $(j-1)$ of associated binary logistic regression models for the full proportional odds model, where each split compares $\mathrm{BI}>$ category $j$ to $\mathrm{BI} \leq$ category $j$. The logit effects and the corresponding odds ratios (ORs) of all variables (except for Household income and PBC) are different across all six models comparing the probabilities of being beyond category $j$ versus at or below that category.

The estimated parameters ( $\beta_{j}$ in Equation (3)) presented in Table 6 are only slightly more difficult to interpret than the earlier estimates under the parallel lines assumption, and they provide insights that were obscured before. In particular, the effects of the constrained variables (Household income and $\mathrm{PBC}$ ) can be interpreted much the same as they were previously. For the other predictors, the differences from before are largely a matter of degree. The elaboration results show that the effect of ATT is more extreme on the higher levels of BI, whereas the pattern is reversed for SN and AIR. The effect of these variables is, in fact, more extreme on the lower level of BI. With all estimates positive, the higher the ATT, SN, and AIR, the higher the BI. Furthermore, as previously ascertained, males tend to be less favorable to buying a longevity annuity than are females, even though their pattern is more complicated. They are less likely to report lower purchase intention than are females, but they are also less likely to report the highest purchase intention. Finally, the effect of Education is significant and positive only in correspondence with the highest category of BI.

Table 7. Partial proportional odds model estimates.

\begin{tabular}{|c|c|c|c|c|c|c|}
\hline & $\mathrm{BI}>\mathbf{1}$ & $\mathrm{BI}>2$ & $\mathrm{BI}>3$ & $\mathrm{BI}>4$ & $\mathrm{BI}>5$ & $\mathrm{BI}>6$ \\
\hline ATT & $0.736^{* * *}$ & $0.874^{* * *}$ & $1.001 * * *$ & $1.169^{* * *}$ & $1.526^{* * *}$ & $1.496^{* * *}$ \\
\hline $\mathrm{SN}$ & $0.465^{* * *}$ & $0.401^{* * *}$ & $0.370^{* * *}$ & $0.339^{* * *}$ & $0.275^{* * *}$ & $0.148^{* *}$ \\
\hline PBC & $0.149^{* * *}$ & $0.149^{* * *}$ & $0.149^{* * *}$ & $0.149^{* * *}$ & $0.149 * * *$ & $0.149 * * *$ \\
\hline AIR & $0.639 * * *$ & $0.612 * * *$ & $0.529^{* * *}$ & $0.396^{* * *}$ & $0.295^{* * *}$ & $0.112 * *$ \\
\hline Gender $(1=\mathrm{M})$ & -0.086 & $-0.255^{* * *}$ & $-0.321^{* * *}$ & -0.033 & -0.131 & $-0.282 *$ \\
\hline Household income $(1=$ low $)$ & -0.01 & -0.01 & -0.01 & -0.01 & -0.01 & -0.01 \\
\hline Education $(1=$ low $)$ & -0.285 & 0.206 & -0.035 & 0.081 & 0.267 & $0.726^{* * *}$ \\
\hline Constant & $2.402 * * *$ & $1.054^{* * *}$ & $0.291^{* * *}$ & $-1.215^{* * *}$ & $-2.815^{* * *}$ & $-4.270^{* * *}$ \\
\hline$\chi^{2}(\mathrm{df})$ & \multicolumn{6}{|c|}{$4567(32)$} \\
\hline Pseudo $R^{2}$ & \multicolumn{6}{|c|}{0.226} \\
\hline $\mathrm{N}$ & \multicolumn{6}{|c|}{7480} \\
\hline
\end{tabular}

Notes: ${ }^{*} p<0.05 ;{ }^{* *} p<0.01 ;{ }^{* * *} p<0.001$.

\section{Discussion}

To the best of our knowledge, this is the first study employing the TPB to explore the motivational processes underlying the intention to buy longevity annuities. Part of the value of this study resides, therefore, in broadening the field of application of the TPB, confirming its predictive validity also within the financial domain and specifically that of longevity annuity buying. Furthermore, the study provides a contribution to the extant literature on the TPB model ascertaining the significant influence of affective determinants on behavioral intention and revealing that intention varies among different consumer segments based on gender and educational level. The research outcomes also reveal that the influence of some of the investigated explanatory variables, namely attitude, subjective norms, and anticipated inaction regret, varies alongside individuals' likelihood to behave. Finally, whereas the bulk of previous works - mainly of a financial type — have investigated elderly annuity-buying behavior, 
the current study concentrates on young adults, who are most penalized by the latest pension system reforms taking place all over the world and thus constitute a relevant object of enquiry. This study may therefore provide original theoretical implications and recommendations for designing both public and private interventions to promote young people's financial self-protection.

\subsection{Theoretical Implications}

All three fundamental constructs of the TPB have been found relevant to predict longevity annuity-buying intention, confirming the validity of such a model in the financial domain as well. Furthermore, the affective component has been found to be a significant predictor of intention to behave, validating the outcomes of prior research testing the sufficiency of the TPB model and highlighting the role that emotion-based constructs may have in influencing people's decisional processes. Such a result corroborates as well the behavioral finance notion that individuals do not make investment decisions exclusively based on rational considerations, but feelings do affect their decision-making. The moderating effect of gender and educational level has also been ascertained, confirming that some background factors, such as socio-demographic characteristics, can play a role in shaping people's decisional processes.

All investigated variables have been found to be positively related to intention to behave, meaning that the more positive the attitude, the higher the subjective norm and the perceived behavioral control, and the greater the anticipated inaction regret, the higher the likelihood to engage in the buying behavior on the part of individuals. Nevertheless, the findings also show that the influence of the investigated constructs varies alongside people's willingness to behave. In particular, whereas perceived behavioral control exerts a constant influence on all investigated people, attitude more strongly affects individuals who are more willing to enroll in a private pension program, while social pressure and anticipated inaction regret more intensively influence individuals who are less willing to annuitize. In addition to the findings that confirm prior studies, these latter outcomes could have interesting theoretical implications. Almost all studies on the TRA and the TPB, as well as those including further constructs to increase the predictive power of these models, test the influence that the investigated explanatory variables exert on behavioral intention through methods that provide a yes or no type of answer and measure the overall magnitude of this influence. Differently, the results of this research reveal that the investigated constructs do have an influence on intention to behave and that the extent of this influence varies alongside the degree of behavioral intention. In other words, the findings suggest that attitude, subjective norms, anticipated inaction regret, and possibly any other behavioral antecedent may have different effects on people who claim to have dissimilar (higher or lower) intention to implement an investigated behavior. If this is the case, it means that intention degree does not only provide information about the higher or lower likelihood to engage in a behavior. Nonetheless, given that there is a relationship between intention level and the strength exerted by behavioral intention antecedents, it could also allow discriminating between people characterized by different motivational structures, i.e., people who claim to be more or less willing to implement the behavior are also more or less influenced by certain behavioral predictors.

With specific reference to the present study, the obtained results could be explained by considering the characteristics of the investigated product, i.e., a complex and unsought product. In fact, compared with immediate annuities for retirees, whose benefits start being paid out immediately after the first disbursement, longevity annuities for young adults provide benefits that are deferred in time (in this case, a long time) and are therefore aimed at fulfilling a need that is not yet perceived. Complexity, lack of familiarity, and absence of tangible benefits realized at purchase could be why people who are more likely to engage in the buying behavior are more influenced by the positive appraisal they hold about the behavior in question. Given that attitude formation is based on a cognitive, information-processing activity implemented by people who reasonably consider the outcomes of their actions and ponder each outcome's desirability, it might be that those who are more willing to buy the annuity policy have already gone through this evaluative process. They are probably more knowledgeable and familiar 
with the product and more influenced by the positive assessment they have formed based on their evaluation of the policy functional benefits. Those instead who are less knowledgeable and do not yet hold a positive attitude toward the product rely more strongly on emotions and on the opinion of their salient referents. In other words, they tend to be more influenced by non-rational behavioral antecedents and perceived social pressure. A few further reasons could explain why social pressure is a significant predictor of annuity-buying intention. The first relates to the age of the investigated consumers. Prior research on the youngsters has, in fact, already highlighted the relevant impact that the social context has on young people's decision making [76]. Second, as claimed by Bansal and Taylor [77], in addition to the influence of attitude, normative influence may be particularly relevant in service settings. Given that longevity annuities are services and, as said, complex services, the already mentioned lack of familiarity and prior experience with these products could potentially be at the basis of a higher perceived risk, which could spur people to rely on possible guidance from salient referents. Perceived risk could be plausibly higher for those who have not yet formed a positive appraisal of the product, increasing the relevance they attribute to important others' advice.

\subsection{Managerial and Policy Implications}

The obtained results provide interesting implications both at the managerial and the policy level. Individuals who are more willing to buy a contract of financial coverage hold more-positive attitudes toward the purchasing behavior and are more strongly affected by their attitude. Considering that these individuals have consciously pondered the functional benefits provided by annuities means they positively assess the warranty of a reliable income throughout their advanced life. Given the relationship between attitudes and beliefs, interventions designed to strengthen people's buying intention should therefore aim to favor the formation of favorable beliefs toward buying annuities as well as increase the perceived value attributed to the related outcomes. This goal could be achieved by combining persuasive communication strategies with those that are solely informative. Messages could focus on the advantages attainable by subscribing to a policy, such as the capability to achieve investment earnings that exceed inflation, maintain satisfying standards of living, and afford health care expenses, exploiting positive framing techniques. However, negative framing techniques could also be profitably exploited. In this case, messages should emphasize the possible negative consequences coming from not annuitizing, such as outliving one's own savings, being unable to afford health care expenses, etc. Taking into consideration also the influence of anticipated inaction regret found in this research, it could in fact be that in some circumstances, pointing out the undesirable outcomes of lacking the resources to have a comfortable late life could constitute more-convincing arguments than the outcomes that are solely desirable.

The importance the reliance upon others has in the annuity-buying decision-making process, especially for those who are less willing to annuitize, suggests that in addition to the traditional marketing strategies used to push annuities-based on a well-trained sales force and aggressive personal selling tactics of a one-to-one type-companies could profitably target groups of people, such as households or groups of peers and mates. Analogously, at the policy level, educational campaigns involving groups of people such as classes in schools or universities as well as worker categories could be more effective than targeting single individuals. Initiatives of this kind have been carried on in Italy; however, they are said to still be inappropriate for the population needs $[15,78]$. Finally, given the relevance of Internet-based human relationships, such as those enabled by social networks, both companies and educators should carefully evaluate the possibility of enhancing their use of digital technologies and direct their messages through modern ICT channels as well.

Anticipated inaction regret is also relevant in the decision-making process of buying a longevity annuity, and analogously to subjective norms, its relevance is higher for individuals who are less willing to annuitize. Some considerations can be made regarding the kind of emotions investigated in the study. The anticipated affective reactions examined in the present research, namely, guilt and regret, could in fact be linked to individuals' sense of duty to engage behavior that will provide 
positive outcomes not only for themselves but also for others. Although longevity annuity buying cannot be properly defined as a pro-social behavior [79], such as blood donation or charity, there is no doubt that the possible negative consequences from not annuitizing can impact subjects other than the potential buyer. As said, both the present society and the economy of a country, as well as that of future generations, could be negatively impacted by the inability of people to set aside enough resources to support their late life. Furthermore, he/she not annuitizing could adversely affect close relatives of the potential subscriber as well. This seems to be especially true in Italy, where the long-term care system for the elderly is characterized by a high level of institutional fragmentation and a significant share of the related expenditure is funded directly by households [80]. In this case, anecdotal evidence negatively framing the effects of not annuitizing could fruitfully spur people to subscribe to a policy. Furthermore, similarly to what is done in health education campaigns or in the field of security prevention, messages could be based on fear-arousing appeals. According to the literature, in fact, high-fear messages are said to induce more attitude, intention, and behavior change than low-fear messages e.g., [81,82]. Making individuals concerned about the consequences of lacking insurance coverage for their late life could represent an effective method to increase their subscription rate.

Finally, the study results confirm the relevance of perceived control on the intention to buy longevity annuities and reveal that it equally impacts all investigated people. Thus, purchasing behavior could be hindered because people perceive that they lack the adequate skills and resources to buy annuities. Accordingly, interventions should aim to improve people's competencies and help them overcome other perceived barriers. While it is quite unrealistic that companies and policy makers can intervene directly on some factors, such as time, energy, and money that people can dedicate to the purchase of longevity annuities, they can more feasibly work to improve people's skills. In this case, communication campaigns based on persuasion techniques would not be the most effective to bring about changes in these factors. Rather, it may prove fruitful to train people to develop the appropriate skills to understand the policy's functioning and increase their familiarity with the product. In other words, in relation to self-efficacy, both companies and governments could more profitably employ more-traditional tools aimed at increasing people's financial literacy, such as wide-spectrum educational campaigns.

The final considerations relate to the socio-demographic characteristics that have been found to influence people's intention to annuitize and, therefore, are related to the opportunity to differentiate both the value propositions of companies and the communication campaigns of policy makers based on the targeted audience. Surprisingly, possessing a lower educational level increases the likelihood of being more willing to subscribe to a longevity annuity policy. Despite the multiple contributions that link a higher educational level with a higher propensity to subscribe to financial products, this result might have a more complex, socially related explanation. According to recent studies [83,84], individuals with a lower socio-economic status often work in more-physically demanding jobs. Moreover, due to work stress, lack of personal control on the job, and the related health problems, they may have a lesser capacity to remain in the workforce. Given that achievable work positions strictly depend on a person's educational level [85], it might be that interviewed people (possessing a lower education) are aware that they will not be able to have a comfortable job position along their work life and might, more than others, be in need of insurance coverage to provide the necessary assets for their advanced life. It is quite plausible that these people are price-sensitive. Therefore, companies could effectively use promotional initiatives, such as discounts, monetary incentives, and favorable payment arrangements and plans, to leverage the price sensitivity of prospects. Furthermore, grounded on these results, companies should make special arrangements for certain categories of workers employed based on the same collective labor agreement. Although it is a quite consolidated practice that insurance or financial companies sign special agreements with large enterprises, reserving ad hoc contractual conditions to their employees, such bargains often end up excluding a considerable share of a country's workforce. Analogously to Italy, in fact, in multiple other countries, small and medium 
enterprises are the dominant business type [86]. Usually, smaller organizations are unable to dialog with larger insurance or financial companies that have greater bargaining power. Thinking instead about transversal agreements, including people who have the same employment status regardless of their place of work would neutralize the disparities due to being hired by a small or medium enterprise rather than a large company. Curiously, this mirrors exactly what was done in the first half of the twentieth century by the INA (Istituto Nazionale delle Assicurazioni, the public authority dominating the Italian market for life insurance at the time) [87]. In those years, dominated by the self-sufficiency policy of Mussolini, special annuities were thought to fulfill specific worker category needs. This is why old documents are related to annuities and life insurance customized for miners, farmers, and even chimney sweeps.

Finally, being male reduces the chances of being keen to annuitize. This result is different from the data at the national level where women holding a longevity annuity represent $43.2 \%$ of total subscribers aged 25-34. However, it is worth noting that whereas the official data refers to the number of actual policyholders, our study investigated the intention to purchase a longevity annuity. A possible explanation could be that women are less likely than men to translate intentions into actions (behavior-intention gap). This could be because in Italy both employment rates and earning levels are less favorable for women [88], making it more difficult for them to save for retirement. In any case, considering the gender-related result obtained in this study, we acknowledge that it is compliant with the outcomes of prior studies where women were found to be more risk averse, less financially literate, and hold a higher degree of anxiety in financial decisions than men [1]. Therefore, it could be that females are more in favor of enrolling in privately held pension funds because they are more worried than males about the possibility of outliving their savings. Additionally, they would tend to choose more often relatively less-risky products, such as longevity annuities, rather than other types of more hazardous investments. In this case, the reassurance about the low risk of these products could represent a valuable argument to spur buying behavior. Based on framing research, appeals to women could profitably focus on the security of a predictable and reliable income that will last for their entire late life. Furthermore, the policy option providing a lump-sum disbursement in case of premature death of the annuitant could constitute an additional argument of conviction fulfilling possible bequeath motives. Finally, because social pressure also significantly affects buying intention, especially for those who are less willing to annuitize, women should be regarded as a priority target by insurance companies and public institutions. Once persuaded about the importance of subscribing to a longevity annuity, they could represent relevant endorsers who could possibly become influencers of friends and close relatives, ending up increasing their subscription rate as well.

\section{Limitations and Suggestions for Future Research}

The findings of this research need to be interpreted in light of some limitations. The first limitation is that the survey design was based on a purposive sampling method; therefore, the findings have to be generalized with caution. However, the study is useful in revealing the influence that the affective component and some socio-demographic factors may exert on behavioral intention. To generalize the obtained findings, future studies could work on statistically significant samples. Because a variable influence of behavioral intention predictors based on intention degree was found in this study, future studies on general buying behavior should take into account that the explanatory variables considered in their models could have different weights in the decision-making process of people according to their higher or lower inclination to behave. At an empirical level, this means that the degree of behavioral intention could be fruitfully considered to craft appropriate marketing strategies focusing on the variables that are more important in shaping people's possible future conduct. With specific reference to the type of product investigated in the present study, two considerations can be made. First, longevity annuities are just one of the multiple products that enable retirement coverage. Future researches could fruitfully investigate more than one type of supplemental retirement investment to ascertain whether there is a difference in people's attitudes and behavioral intention based on the product type. Second, 
given that longevity annuities are unsought products, future studies on unsought goods and services could verify whether the obtained findings hold true for other types of unsought complex products. Furthermore, this study investigated the intention to buy a longevity annuity and not consumers' overt behavior. Although the performance of a given behavior is claimed to be primarily determined by the strength of a person's intention to perform that behavior, no test of the relationship between intention and actual purchasing behavior was made in this study. Future studies could profitably investigate the existence of a possible behavior-intention gap. Finally, given the social sensitivity of the matter investigated in the present study and the direct interview methodology used in the survey, investigators should include some measures to prevent possible social desirability biases to minimize the risk of obtaining socially acceptable answers.

Acknowledgments: The authors are grateful to the three anonymous reviewers for their valuable and constructive comments that contributed to improving the final version of the manuscript. This work was supported by the Personal Research Funding Parthenope University of Naples.

Author Contributions: C.N. and C.A.P. conceived and designed the research, and collected the data; A.D. and M.P. made the statistical analysis of the data. Specifically, C.N. wrote Sections 1-5, 8.1 and 9; A.D. and M.P. wrote Sections 6 and 7; C.N. and C.A.P. wrote Section 8.2.

Conflicts of Interest: The authors declare no conflict of interest.

\section{References}

1. Fornero, E.; Monticone, C. Financial literacy and pension plan participation in Italy. J. Pension Econ. Financ. 2011, 10, 547-564. [CrossRef]

2. Tian, Y.; Zhao, X. Stochastic forecast of the financial sustainability of basic pension in China. Sustainability 2016, 8, 46. [CrossRef]

3. Brown, J.R.; Warshawsky, M.J. Longevity-Insured Retirement Distributions from Pension Plans: Market and Regulatory Issues; Working Paper No. 8064; National Bureau of Economic Research: Cambridge, MA, USA, 2001.

4. Deloitte. 2015 Life Insurance and Annuity Industry Outlook, Taking the Longer-Term View. Available online: https://www2.deloitte.com/content/dam/Deloitte/global/Documents/Financial-Services/gxfsi-outlook-life-insurance.pdf (accessed on 18 April 2016).

5. Stewart, F. Policy Issues for Developing Annuities Markets; OECD Working Papers on Insurance and Private Pensions No. 2; OECD Publishing: Paris, France, 2007.

6. Ajzen, I. The theory of planned behavior. Organ. Behav. Hum. Decis. Process. 1991, 50, 179-211. [CrossRef]

7. Abraham, C.; Sheeran, P. Acting on intentions: The role of anticipated regret. Br. J. Soc. Psychol. 2003, 42, 495-511. [CrossRef] [PubMed]

8. Borella, M.; Moscarola, F.C. The 2011 Pension Reform in Italy and Its Effects on Current and Future Retirees; Working Paper N. 151/15; Center for Research on Pensions and Welfare Policies: Turin, Italy, 2015. Available online: http://www.cerp.carloalberto.org/wp-content/uploads/2015/09/WP_151.pdf (accessed on 19 May 2017).

9. Lanoo, K.; Barslund, M.; Chmelar, A.; von Werder, M. Pension Schemes; Policy Department A: Economic and Scientific Policy European Parliament: Brussels, Belgium, 2015.

10. COVIP. Relazione per L'anno 2015. Available online: http://www.covip.it/wp-content/files_mf/ 1465467659RelazioneAnnuale2015.pdf (accessed on 25 May 2017).

11. COVIP. Relazione per L'anno 2012. Available online: http://www.covip.it/wp-content/files_mf/ 1370858801RelazioneAnnuale2012.pdf (accessed on 25 May 2017).

12. ISTAT. Banca Dati Popolazione e Famiglie. Available online: http://dati.istat.it/ (accessed on 25 May 2017).

13. COVIP. Relazione per L'anno 2013. Available online: http://www.covip.it/wp-content/files_mf/ 1401285597RA2013_ConsPres.pdf (accessed on 25 May 2017).

14. COVIP. Relazione per L'anno 2014. Available online: http://www.covip.it/wp-content/files_mf/ 1434012965RelazioneAnnuale2014.pdf (accessed on 25 May 2017).

15. Assoprevidenza. Sviluppare la Previdenza Complementare Favorisce la Crescita Economica; Assoprevidenza Previdenza Italia: Rome, Italy, 2011. 
16. Kotler, P.; Armstrong, G.; Wong, V.; Saunders, J.A. Principles of Marketing; Pearson Education: Essex, UK, 2008.

17. Kearney, A.K. The European Life-Insurance Industry. Charting a New Course to Defeat Market Challenges. 2010. Available online: https://www.atkearney.de/documents/856314/1214692/BIP_The_European_LifeInsurance_Industry.pdf/3d4f1944-7075-4b65-952a-3b096fb6dfdf (accessed on 19 April 2016).

18. Osman, A.; Othman, Y.H.; Rana, S.M.S.; Jin, L.Y.; Solaiman, M. Effectiveness of promotional tools to influence the purchase decisions of unsought products: A study of life insurance. Soc. Sci. 2016, 11, 87-92.

19. Fishbein, M.; Ajzen, I. Belief, Attitude, Intention, and Behavior: An Introduction to Theory and Research; Addison-Wesley: Reading, MA, USA, 1975.

20. Fitzmaurice, J. Incorporating consumers' motivations into the theory of reasoned action. Psychol. Mark. 2011, 22, 911-929. [CrossRef]

21. Van Winden, F.; Krawczyk, M.; Hopfensitz, A. Investment, resolution of risk, and the role of affect. J. Econ. Psychol. 2011, 32, 918-939. [CrossRef]

22. Hetts, J.J.; Boninger, D.S.; Armor, D.A.; Gleicher, F.; Nathanson, A. The influence of anticipated counterfactual regret on behavior. Psychol. Mark. 2000, 17, 345-368. [CrossRef]

23. Richard, R.; van der Pligt, J.; de Vries, N.K. Anticipated regret and time perspective: Changing sexual risk-taking behavior. J. Behav. Decis. Mak. 1996, 9, 185-199. [CrossRef]

24. Conner, M.; Abraham, C. Conscientiousness and the theory of planned behavior: Toward a more complete model of the antecedents of intentions and behavior. Pers. Soc. Psychol. Bull. 2001, 27, 1547-1561. [CrossRef]

25. Conner, M.; Sandberg, T.; McMillan, B.; Higgins, A. Role of anticipated regret, in adolescent smoking initiation. Br. J. Health Psychol. 2006, 11, 85-101. [CrossRef] [PubMed]

26. O'Connor, R.C.; Armitage, C.J. Theory of planned behaviour and parasuicide: An exploratory study. Curr. Psychol. 2003, 22, 196-205. [CrossRef]

27. Ajzen, I. From intentions to actions: A theory of planned behavior. In Action-Control: From Cognition to Behavior; Kuhi, J., Beckmann, J., Eds.; Springer: Heidelberg, Germany, 1985; pp. 11-39.

28. Ajzen, I.; Fishbein, M. Understanding Attitudes and Predicting Social Behaviour; Prentice-Hall: Englewood Cliffs, NJ, USA, 1980.

29. Eagly, A.H.; Chaiken, S. The Psychology of Attitudes; Harcourt Brace Jovanovich: Fort Worth, TX, USA, 1993.

30. Bang, H.K.; Ellinger, A.E.; Hadjimarcou, J.; Traichal, P.A. Consumer concern, knowledge, belief, and attitude toward renewable energy: An application of the reasoned action theory. Psychol. Mark. 2000, 17, 449-468. [CrossRef]

31. Wood, W.; Hayes, T. Social influence on consumer decisions: Motives, modes, and consequences. J. Consum. Psycol. 2012, 22, 324-328. [CrossRef]

32. Hrubes, D.; Ajzen, I.; Daigle, J. Predicting hunting intentions and behavior: An application of the theory of planned behavior. Leis. Sci. 2001, 23, 165-178. [CrossRef]

33. Cook, A.J.; Kerr, G.N.; Moore, K. Attitudes and intentions towards purchasing GM food. J. Econ. Psychol. 2002, 23, 557-572. [CrossRef]

34. Ho, C.-W.; Wang, Y.-B.; Yen, N.Y. Does environmental sustainability play a role in the adoption of smart card technology at universities in Taiwan: An integration of TAM and TRA. Sustainability 2015, 7, 10994-11009. [CrossRef]

35. Dawkins, C.E.; Jamali, D.; Karam, C.; Lin, L.; Zhao, J. Corporate Social Responsibility and job choice intentions: A cross-cultural analysis. Bus. Soc. 2016, 55, 854-888. [CrossRef]

36. Nadlifatin, R.; Lin, S.-C.; Rachmaniati, Y.P.; Persada, S.F.; Razif, M. A pro-environmental reasoned action model for measuring citizens' intentions regarding ecolabel product usage. Sustainability 2016, 8, 1165. [CrossRef]

37. Conner, M.; Sparks, P. Ambivalence and attitudes. Eur. Rev. Soc. Psychol. 2002, 12, 37-70. [CrossRef]

38. Baumgartner, H.; Pieters, R.; Bagozzi, R.P. Future-oriented emotions: Conceptualization and behavioral effects. Eur. J. Soc. Psychol. 2008, 38, 685-696. [CrossRef]

39. Biel, A.; Thøgersen, J. Activation of social norms in social dilemmas: A review of the evidence and reflections on the implications for environmental behavior. J. Econ. Psychol. 2007, 28, 93-112. [CrossRef]

40. Beck, L.; Ajzen, I. Predicting dishonest actions using the theory of planned behavior. J. Res. Pers. 1991, 25, 285-301. [CrossRef]

41. Armitage, C.J.; Conner, M. The theory of planned behavior: Assessment of predictive validity and perceived control. Br. J. Soc. Psychol. 1999, 38, 35-54. [CrossRef] 
42. May, D.R.; Pauli, K.P. The role of moral intensity in ethical decision making: A review and investigation of moral recognition, evaluation, and intention. Bus. Soc. 2002, 41, 84-117. [CrossRef]

43. Zeelenberg, M.; Pieters, R. Consequences of regret aversion in real life: The case of the Dutch postcode lottery. Organ. Behav. Hum. Decis. 2004, 93, 155-168. [CrossRef]

44. Kidwell, B.; Jewell, R. The influence of past behaviour on behavioral intent. An information-processing explanation. Psychol. Mark. 2008, 25, 1151-1166. [CrossRef]

45. Agarwal, J.; Malhotra, N.K. An integrated model of attitude and affect. J. Bus. Res. 2005, 58, 483-493. [CrossRef]

46. Conner, M.; Armitage, C.J. Extending the theory of planned behavior: A review and avenues for further research. J. Appl. Soc. Psychol. 1988, 28, 1429-1464. [CrossRef]

47. Conner, M. Cognitive Determinants of Health Behavior. In Handbook of Behavioral Medicine. Methods and Applications; Steptoe, A., Ed.; Springer Science + Media: New York, NY, USA, 2010; pp. 19-30.

48. Richetin, J.; Conner, M.; Perugini, M. Not doing is not the opposite of doing: Implications for attitudinal models of behavioral prediction. Pers. Soc. Psychol. Bull. 2011, 37, 40-54. [CrossRef] [PubMed]

49. Sandberg, T.; Conner, M. Anticipated regret as an additional predictor in the theory of planned behaviour: A meta-analysis. Br. J. Soc. Psychol. 2008, 47, 589-606. [CrossRef] [PubMed]

50. Rivis, A.; Sheeran, P.; Armitage, C.J. Expanding the affective and normative components of the theory of planned behavior: A meta-analysis of anticipated affect and moral norms. J. Appl. Soc. Psychol. 2009, 39, 2985-3019. [CrossRef]

51. Lance, C.E.; Butts, M.M.; Michels, L.C. The sources of four commonly reported cutoff criteria: What did they really say? Organ. Res. Methods 2006, 9, 202-220. [CrossRef]

52. Nunnally, J.C. Psychometric Theory, 1st ed.; McGraw-Hill: New York, NY, USA, 1967.

53. Peterson, B.; Harrell, F.E., Jr. Partial proportional odds models for ordinal response variables. Appl. Stat. 1990, 39, 205-217. [CrossRef]

54. Nosi, C.; D'Agostino, A.; Pagliuca, M.; Pratesi, C.A. Saving for old age: Longevity annuity buying intention of Italian young adults. J. Behav. Exp. Econ. 2014, 51, 85-98. [CrossRef]

55. Bartholomew, D.; Knotts, M.; Moustaki, I. Latent Variable Models and Factor Analysis: A Unified Approach, 3rd ed.; John Wiley \& Sons: West Sussex, UK, 2011.

56. Yong, G.; Pearce, S. A Beginner's guide to factor analysis: Focusing on exploratory factor analysis. Tutor. Quant. Methods Psychol. 2013, 9, 79-94. [CrossRef]

57. West, S.G.; Taylor, A.B.; Wu, W. Model Fit and Model Selection in Structural Equation Modeling. In Handbook of Structural Equation Modeling; Hoyle, R.H., Ed.; Guilford: New York, NY, USA, 2012; pp. 209-246.

58. Kenny, D.A. Measuring Model Fit. 2012. Available online: http://www.davidakenny.net $/ \mathrm{cm} / \mathrm{fit} . \mathrm{htm}$ (accessed on 4 May 2016).

59. Browne, M. Covariance Structures. In Topics in Applied Multivariate Analysis; Hawkins, D.M., Ed.; Cambridge University Press: Cambridge, UK, 1982; pp. 72-141.

60. Bentler, P.M.; Yuan, K.H. Structural equation modeling with small samples: Test statistics. Multivar. Behav. Res. 1999, 34, 183-199. [CrossRef] [PubMed]

61. Browne, M. Asymptotically distribution-free methods for the analysis of covariance structures. Br. J. Math. Stat. Psychol. 1984, 37, 62-83. [CrossRef] [PubMed]

62. Sugawara, H.M.; MacCallum, R.C. Effect of estimation method on incremental fit indexes for covariance structure models. Appl. Psychol. Meas. 1993, 17, 365-377. [CrossRef]

63. Tello, F.P.H.; Moscoso, S.C.; García, I.S.; Abad, E.V. Polychoric versus Pearson correlations in exploratory and confirmatory factor analysis of ordinal variables. Qual. Quant. 2010, 44, 153-166. [CrossRef]

64. Di Stefano, C.; Zhu, M.; Mîndrilă, D. Understanding and using factor scores: Considerations for the applied researcher. Pract. Assess. Res. Eval. 2009, 14, 11.

65. Liu, X. Ordinal regression analysis: Fitting the proportional odds model using Stata, SAS and SPSS. J. Mod. Appl. Stat. Methods 2009, 8, 632-645.

66. Long, J.S. Regression Models for Categorical and Limited Dependent Variables; Sage: Thousand Oaks, CA, USA, 1997.

67. Brant, R. Assessing proportionality in the proportional odds model for ordinal logistic regression. Biometrics 1990, 46, 1171-1178. [CrossRef] [PubMed]

68. Fu, V. Estimating generalized ordered logit models. Stata Tech. Bull. 1998, 44, 27-30. 
69. Williams, R. Generalized ordered logit/partial proportional odds models for ordinal dependent variables. Stata J. 2006, 6, 58-82.

70. Brown, T.A. Confirmatory Factor Analysis for Applied Research; Guilford: New York, NY, USA, 2006.

71. Schermelleh-Engel, K.; Moosbrugger, H.; Müller, H. Evaluating the fit of structural equation models: Tests of significance and descriptive goodness-of-fit measures. Methods Psychol. Res. Online 2003, 8, $23-74$.

72. Hu, L.T.; Bentler, P.M. Cutoff criteria for fit indexes in covariance structure analysis: Conventional criteria versus new alternatives. Struct. Equ. Model. 1999, 6, 1-55. [CrossRef]

73. Kleinbaum, D.G.; Kupper, L.; Muller, K.E. Applied Regression Analysis and Other Multivariable Methods, 2nd ed.; PWS-Kent: Boston, MA, USA, 1988.

74. Ajzen, I. Consumer attitudes and behavior: The theory of planned behavior applied to food consumption decisions. Riv. Econ. Agric. 2015, 2, 121-138.

75. Cooke, R.; Dahdah, M.; Norman, P.; French, M.P. How well does the theory of planned behaviour predict alcohol consumption? A systematic review and meta-analysis. Health Psychol. Rev. 2016, 10, 148-167. [CrossRef] [PubMed]

76. Mandrik, C.A.; Fern, E.F.; Bao, Y. Intergenerational influence: Roles of conformity to peers and communication effectiveness. Psychol. Mark. 2005, 22, 813-832. [CrossRef]

77. Bansal, H.S.; Taylor, S.F. Investigating interactive effects in the theory of planned behavior in a service-provider switching context. Psychol. Mark. 2002, 19, 407-425. [CrossRef]

78. Farsagli, S.; Traclò, F. (Eds.) Le Esperienze di Educazione Finanziaria. Indagine Sulla Realtà Italiana nel Contesto Internazionale; Consorzio PattiChiari: Rome, Italy, 2011.

79. Penner, L.A.; Dovidio, J.F.; Piliavin, J.A.; Schroeder, D.A. Prosocial behavior: Multilevel perspectives. Annu. Rev. Psychol. 2005, 56, 365-392. [CrossRef] [PubMed]

80. Tediosi, F.; Gariele, S. The Long-Term Care System for the Elderly in Italy. ENEPRI Research Report No. 80. 2010. Available online: http://www.ancien-longtermcare.eu/sites/default/files/ENEPRI\%20_ANCIEN_ \%20RR\%20No\%2080\%20Italy\%20edited\%20final.pdf (accessed on 3 September 2016).

81. De Hoog, N.; Stroebe, W.; de Wit, J.B.F. The impact of vulnerability to and severity of a health risk on processing and acceptance of fear-arousing communications: A meta-analysis. Rev. Gen. Psychol. 2007, 11, 258-285. [CrossRef]

82. Witte, K.; Allen, M. A meta-analysis of fear appeals: Implications for effective public health campaigns. Health Educ. Behav. 2000, 27, 591-616. [CrossRef] [PubMed]

83. Knoll, M.A.Z. Behavioral and psychological aspects of the retirement decision. Soc. Secur. Bull. 2011, 71, 15-32. [PubMed]

84. Li, X.; Hurd, M.; Loughran, D.S. The Characteristics of Social Security Beneficiaries Who Claim Benefits at the Early Entitlement Age; AARP Public Policy Institute Research Report No. 2008-19; AARP: Washington, DC, USA, 2008.

85. OECD. How does educational attainment affect participation in the labour market? In OECD Education at a Glance; OECD Publishing: Paris, France, 2011; pp. 116-136.

86. OECD. Entrepreneurship at a Glance 2014; OECD Publishing: Paris, France, 2014.

87. Pratesi, C.A.; Nosi, C. INA Assitalia e il mercato. In 100 Anni di INA Assitalia; Pratesi, C.A., Ed.; Electa Mondadori: Milan, Italy, 2012; pp. 84-115.

88. World Economic Forum. The Global Gender Gap Report 2016. Available online: http:/ / reports.weforum. org/global-gender-gap-report-2016/ (accessed on 27 May 2017).

(C) 2017 by the authors. Licensee MDPI, Basel, Switzerland. This article is an open access article distributed under the terms and conditions of the Creative Commons Attribution (CC BY) license (http://creativecommons.org/licenses/by/4.0/). 